\title{
Amplifying DNA with Arbitrary Oligonucleotide Primers
}

\author{
Gustavo Caetano-Anollés
}

Plant Molecular Genetics, Institute of Agriculture and Center for Legume Research, The University of Tennessee, Knoxville, Tennessee 37901-1071

Genetic molecular markers are DNA segments that behave as landmarks for genome analysis. These segments usually represent variant or polymorphic sites that can be identified using general strategies such as molecular hybridization or enzymatic amplification of DNA. For years, DNA-based diagnostic markers have been used in general organismal identification and in the construction of genetic linkage maps. ${ }^{(1)}$ The widely used restriction fragment length polymorphisms (RFLPs), for example, are molecular markers identified by endonuclease restriction and blot hybridization of DNA. ${ }^{(2)}$ DNA amplification using $\mathrm{PCR}^{(3,4)}$ has also been used extensively in many applications to study polymorphic loci, like hypervariable minisatellites $^{(5)}$ or microsatellites harboring simple sequence repeats, ${ }^{(6-8)}$ and to generate sequence-tagged sites (STSs) ${ }^{(9)}$ for genetic and physical mapping.

Several strategies involving DNA replication, DNA ligation, or RNA transcription have been used for in vitro amplification of nucleic acids. ${ }^{(10-15)}$ However, PCR remains the most widely accepted amplification tool. Primer-directed amplification of DNA, at first used in PCR to amplify cognate regions present at very low levels in the genome, has extended DNA analysis to regions adjacent to sequenced DNA segments, to unknown DNA, and even to the study of RNA-expressed sequences. ${ }^{(15-17)}$ Amplification strategies can be grouped according to the mechanism of the amplification process (Table 1). Amplification with specific primers in the PCR, for example, is a determinate process that requires prior knowledge of the template sequence and targets usually one defined amplification site. Similarly, amplification of interspersed repetitive sequences (IRS), like $A l u-\mathrm{PCR}^{(18)}$ or REP-PCR, ${ }^{(19)}$ are de- terminate processes that target multiple sites of defined sequence in both DNA strands. In contrast, amplification with degenerate primers in random indeterminate amplification processes, like random primed amplification $(\mathrm{RPA}){ }^{(20)}$ primer-extension preamplification (PEP), ${ }^{(21)}$ and random PCR (rPCR), ${ }^{(22)}$ take advantage of stochastic annealing events that randomly amplify nucleic acid stretches or even whole genomes by targeting sites of a noncognate nature. These random DNA amplification procedures are generally used for radioactive or fluorescent labeling of nucleic acids, to increase the amount of DNA in the construction of representative cDNA libraries, or for PCR typing of single haploid cells. Other kinds of amplification processes, although still determinate, do not require prior knowledge of template sequence and can target single or multiple sites in a genome or template molecule. These strategies can use either one arbitrary primer in conjunction with a specific primer (23) or one or more arbitrary primers ${ }^{(24-26)}$ to study single or multiple amplicons, respectively, and can even be extended to the analysis of RNA populations. ${ }^{(27-28)}$ In particular, strategies like gene-walking $\mathrm{PCR}^{(23)}$ and differential CDNA $\mathrm{PCR}^{(27)}$ study specific template regions arbitrary in length but juxtaposed to a known DNA segment defining a specific primer. Like anchored PCR, ${ }^{(29)}$ these hemispecific reactions allow analysis of unknown genomic regions corresponding to mRNA sequences, or adjacent to STSs or sequenced stretches of DNA.

\section{ANALYSIS OF MULTIPLE AMPLICONS OF ARBITRARY NATURE}

The degree of relatedness between individual organisms or inheritance in prog- eny populations can be measured by the variation in length or sequence of DNA segments; however, the identification of these molecular markers requires prior knowledge of DNA sequence, cloned and characterized probes, and considerable experimental manipulation. These limitations can be circumvented with multiple arbitrary amplicon profiling (MAAP) $^{(30)}$ techniques like random amplified polymorphic DNA (RAPD) analysis, ${ }^{(24)}$ arbitrarily primed PCR (AP-PCR), ${ }^{(25)}$ and DNA amplification fingerprinting (DAF). ${ }^{(26)}$ These independently developed strategies use one or more arbitrary oligonucleotide primers to target specific but unknown sites in the genome, many of which are polymorphic. Detected amplification fragment length polymorphisms (AFLPs) can be used easily as markers for genetic typing and mapping applications. ${ }^{(31,32)}$

MAAP techniques target multiple and arbitrary amplicons but differ in primer length, amplification stringency, and procedure used to resolve DNA patterns. For example, AP-PCR ${ }^{(25)}$ uses primers of lengths comparable with those of PCR primers, RAPD ${ }^{(24)}$ analysis uses shorter primers, typically 10 nucleotides in length, and $\mathrm{DAF}^{(26)}$ uses primers as short as 5 nucleotides, but typically 7 or 8 nucleotides in length. These and other differences result in DNA profiles that are clearly distinct. Whereas RAPD resolves few amplification products using agarose gel electrophoresis and ethidium bromide staining, DAF produces characteristic and complex information-rich DNA profiles using polyacrylamide gel electrophoresis and a silver stain that detects DNA at the picogram level. ${ }^{(33)}$ Fingerprints are determined by primer annealing to partially or perfectly complementary sites on each DNA strand. Therefore, primer design, ampli- 
TABLE 1 DNA Polymerase-mediated Nucleic Acid Amplification

\begin{tabular}{|c|c|c|c|c|c|}
\hline \multirow{2}{*}{$\begin{array}{l}\text { Amplification } \\
\text { process }\end{array}$} & \multirow[b]{2}{*}{ Amplicon } & \multicolumn{3}{|c|}{ Primer } & \multirow[b]{2}{*}{ Strategy $^{\mathrm{a}}$} \\
\hline & & number & annealing $^{\mathbf{b}}$ & target (site/strand) & \\
\hline \multirow[t]{4}{*}{ Determinate } & single & two or more & defined/S & specific/one each & PCR \\
\hline & single & two & defined and arbitrary/P & specific/one each & gene-walking PCR \\
\hline & multiple & one or more & defined/S & specific IRS/both & Alu-PCR, REP-PCR, ERIC-PCR \\
\hline & multiple & one or more & arbitrary $/ \mathrm{S}, \mathrm{P}$ & arbitrary/both & DAF, RAPD, AP-PCR \\
\hline Indeterminate & multiple & degenerate & stochastic/P & random/both & RPA, PEP, rPCR \\
\hline
\end{tabular}

${ }^{a}$ Amplification strategies that require additional processes, like vectorette ligation, whole genome PCR, or key PCR, are not listed.

${ }^{b}(S)$ Stringent; $(P)$ permissive. Amplification stringency is defined by reaction conditions (like annealing temperature or primer concentration) that favor specificity during the different cycles of amplification.

fication reaction conditions, and adequate separation and detection of amplified products temper the reproducibility, complexity, and polymorphic content of DNA profiles. ${ }^{(34)}$ For example, RAPD analysis using decamer primers produced fingerprints that were on average 3-10 times less complex than those generated using DAF with decamer and octamer primers. ${ }^{(34)}$

Superficial versus exhaustive examination of amplification products may be partially responsible for differences in profile complexity. However, primer, magnesium, and deoxynucleoside triphosphate concentration, as well as temperature cycling parameters and other amplification reaction components, can alter reaction stringency and dramatically influence both the number and the nature of amplification products.

\section{REACTION MECHANISM}

DNA polymerase-mediated nucleic acid amplification is a complex and dynamic series of chemical reactions where primers single out DNA segments and determine the efficiency of their subsequent amplification. The balance between template, amplification products, enzyme, primers, and deoxynucleoside triphosphate concentration changes with each temperature cycle as amplification products are synthesized and different molecular species interact with each other. Although DNA amplification is most likely a reaction process departing from equilibrium, it may be argued that in every cycle of amplification there are two reaction components, a standard Michaelis-Menten kinetic process discriminating target cognate DNA from noncognate competitor sites, and a virtually irreversible process that is thermodynamically driven by the cleavage of diphosphate from deoxynucleoside triphosphates.

Figure 1 depicts the reaction mechanism proposed by Caetano-Anollés et al. ${ }^{(35)}$ to explain how a single primer amplifies a target genome. The first amplification cycle begins by denaturing the template DNA molecules. Decreasing temperature allows the primer to scan

the DNA for possible annealing sites and to anneal to many of them. Following this "amplicon screening" phase, the thermostable DNA polymerase then anchors and initiates the extension of the annealed primers, producing a defined population of "first-round" amplification products. The discrimination between cognate and noncognate primer-

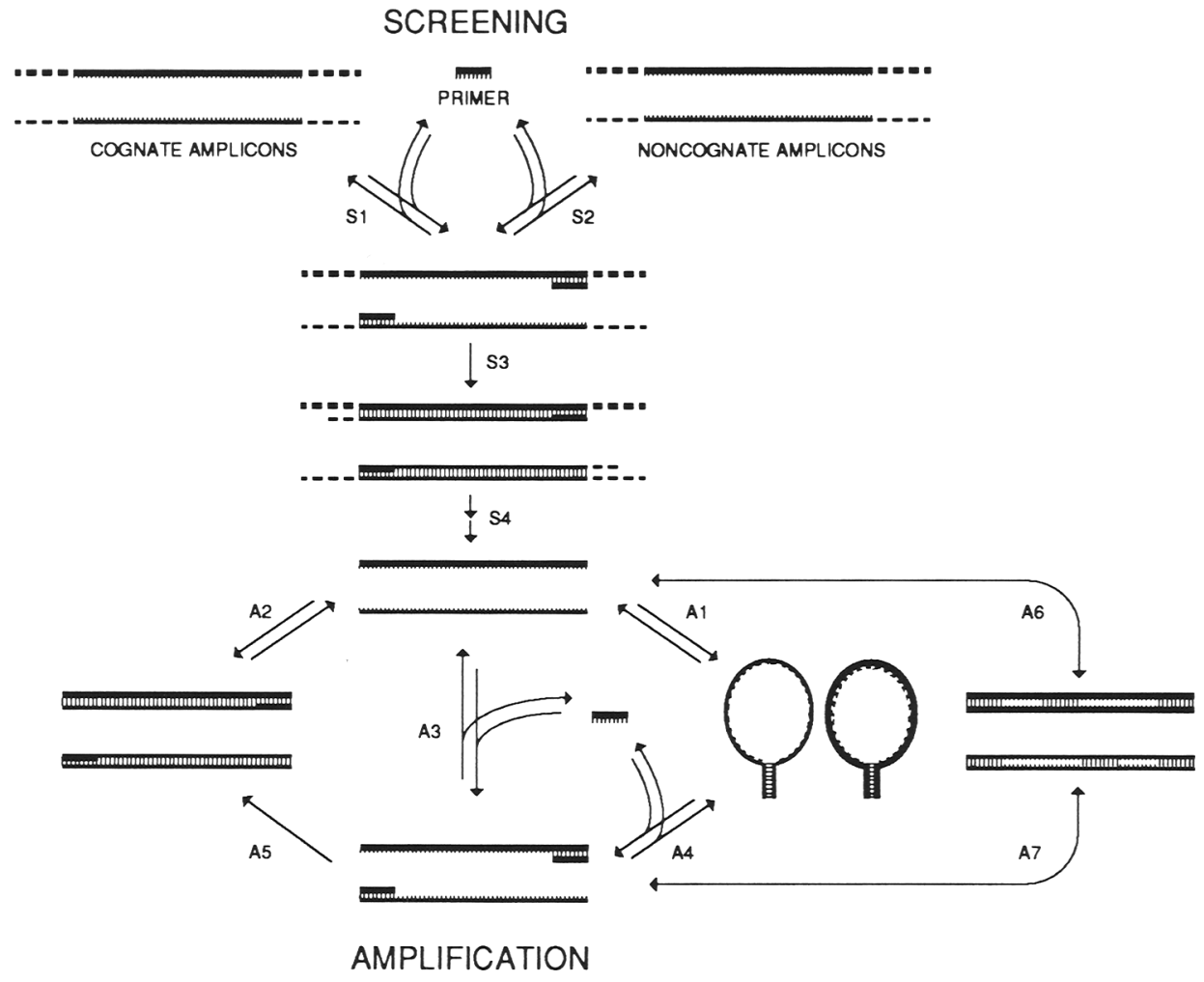

FIGURE 1 Model of interactions between molecular species formed during DNA amplification with a single arbitrary oligonucleotide primer. During a first template "screening" phase (S1, S2) and depending on amplification parameters, cognate and nocognate sites compete and are selected for amplification (S3). The synthesized first-round amplification products (S4) are initially single stranded and have palindromic termini. In subsequent rounds of amplification, the products can establish template-template (A1, A2) and primer-template (A3, A4) interactions. Some interactions may occur late during amplification $(\mathrm{A} 6, \mathrm{~A} 7)$. The different species produced tend to establish an equilibrium. Whereas enzyme anchoring and primer extension (A5) transform the relatively rare primer-template duplexes into accumulating amplification products. In an ideal MAAP amplification, $\mathrm{S} 1>>\mathrm{S} 2$, and $\mathrm{A} 3>\mathrm{A} 1>\mathrm{A} 6$. 
template interactions during the first temperature cycles determines the number and the nature of amplicons selected. A change in the concentration of template DNA or primer will obviously affect amplicon screening, although other components may also influence the reaction.

When amplicons are defined by two primers, first-round amplification products usually become preferred templates and are subsequently amplified with high efficiency. However, single primer amplification products have palindromic termini and, when present in low concentration, can produce hairpin loop structures. Because the primer must displace these hairpin loop complexes long enough for the enzyme to anchor and stabilize the duplex by strand extension, and because the extent of hairpin loop interference will be variable for each fragment, only some of the first-round amplification products will be efficiently amplified.

During late amplification cycles, attenuation in the rate of product accumulation turns exponential amplification into a linear process. This "plateau" phenomenon occurs when the increasing mass of preferred amplification products limits the activity of the polymerase enzyme, reduces the efficiency of template denaturation, increases the $5^{\prime} \rightarrow 3^{\prime}$ single-stranded exonuclease activity of DNA polymerase, and decreases primer annealing by favoring the formation of template duplexes. The high concentration of amplification products also favors reannealing events between the various template molecules. Because DNA template species are independently amplified, amplicons that have been amplifying at low levels are now selected as preferred templates. Therefore, primertemplate interactions become crucial in determining specificity, not only in the presence of a vast molar excess of annealing sites during amplicon screening but also late during amplification when underrepresented amplicons are the only molecular species that are being exponentially amplified.

\section{UNDERSTANDING PRIMER-TEMPLATE INTERACTIONS}

The preferential amplification of an amplicon is driven by the interactions of the primer with its annealing site, followed by appropriate recognition of those interactions by DNA polymerase.
Inefficient extension of primer-template mismatches appears to be caused by failed DNA elongation rather than by a differential enzyme binding affinity of matched versus mismatched termini. ${ }^{(36-39)}$ In structural crystallographic studies of the Klenow fragment, 11 nucleotides of a primer-template duplex were positioned in a groove that lies at right angles to the cleft containing the polymerase active site and adjacent to the $3^{\prime} \rightarrow 5^{\prime}$ exonuclease domain. ${ }^{(40)}$ These and other studies ${ }^{(41,42)}$ suggest that duplex DNA containing the primer $3^{\prime}$ terminus is distorted and is close to the exonuclease site, forcing the primer terminus to shuttle between active sites, whereas the single-stranded template enters from the distal end of the cleft. Mismatches in some of the 19-20 nucleotides of the primer-template duplex proposed to interact with the enzyme ${ }^{(41)}$ are expected to alter extension efficiency. These primer-template mismatches must be identified if we are to understand interactions that drive DNA amplification.

The number and location of primertemplate mismatches (especially if they occur at the $3^{\prime}$ terminus of the primer), their stability at various annealing and extension temperatures, and the efficiency with which the polymerase can recognize and extend the mismatched duplexes have been studied extensively in the PCR process. ${ }^{(38,43-49)}$ However, factors such as the effects of primer length, primer and template conformation, and reaction environment still require careful examination. We used related oligonucleotides differing in length or sequence, and templates engineered to have complementary or mismatched terminal sequences of varying

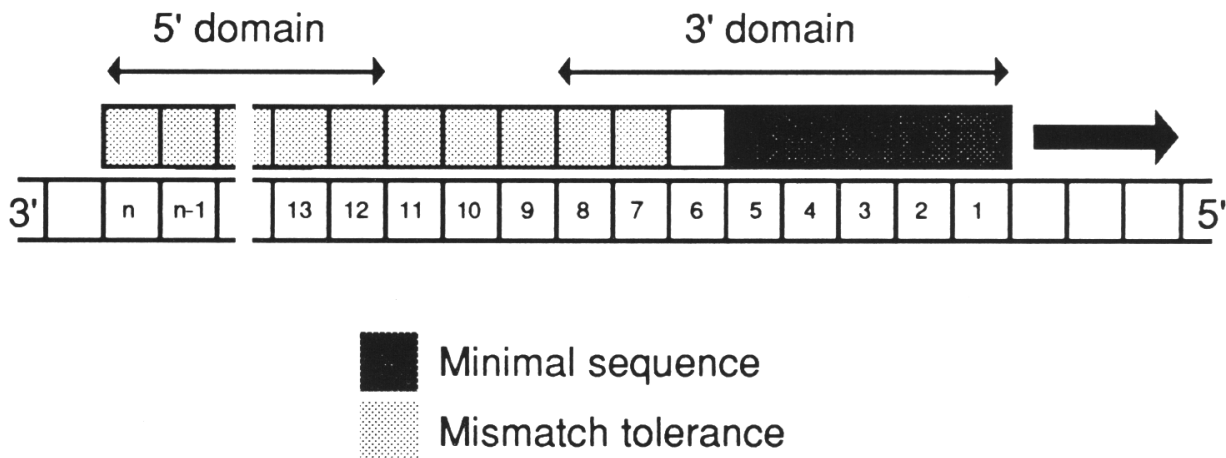

FIGURE 2 Primer-template duplex domains established during amplification of template DNA with arbitrary primers. The arrow indicates the direction of primer extension by DNA polymerase (see text for details). length, to study primer-template interactions established during DAF. ${ }^{(35)}$ The short oligonucleotides used in these experiments approached their functional limits as primers for amplification. Our study defined several domains in the primer-template duplex (Fig. 2). The first 8 nucleotides from the 3' terminus of the primer encompassed a region largely responsible for directing the amplification process. Single base changes in sequence within this domain altered the spectrum of amplification products significantly, especially toward the $3^{\prime}$ terminus. Results show the importance of the 3 '-terminal region of the primer in the DAF reaction and confirm observations for PCR. ${ }^{(49)}$

Whereas successful amplification requires a primer of at least 5 nucleotides in length ${ }^{(26)}$ and annealing sites with perfect homology to the first 5 or $6 \mathrm{nu}$ cleotides from the $3^{\prime}$ terminus, ${ }^{(34)}$ decreasing primer length within the 8-nucleotide domain results in an unpredicted decrease in the number of amplification products and in the production of highly variant fingerprint patterns. In theory, primers of increasing length derived from a common sequence should target subsets of sites recognized by shorter primers, and a common pattern should dominate all fingerprints. As this was not the case, results suggest that only a fraction of template-annealing sites amplify efficiently. ${ }^{(35)} \quad$ Furthermore, certain amplicons are amplified preferentially by short primers due to competition for annealing sites between primer and terminal hairpin loop structures of the template. ${ }^{(35)}$ Primers 8 nucleotides or longer were better able to complete for annealing with hairpin loops.

\section{Mismatch tolerance}


Regions beyond the basic 8-nucleotide domain alter the amplified spectrum only moderately. ${ }^{(35)}$ In particular, the domain is demarcated by a 2 - to 3-nucleotide region over which changes in primer length do not alter fingerprint pattern (Fig. 2). Increasing the primer length does not decrease the number of amplification products. This and the following lines of evidence suggest primertemplate mismatching at the $5^{\prime}$ end of the primer. First, amplification of genomes of high complexity like soybean and human with primers of $>8$ nucleotides in length and of bacteria and fungi with primers of $>7$ nucleotides in length produce many more products than expected. ${ }^{(34)}$ Similarly, primers comparable with those used in PCR produced AP-PCR and RAPD fingerprints from bacterial, fungal, plant, and animal species, ${ }^{(25,50-54)}$ where no products were to be expected on theoretical grounds ${ }^{(34)}$ (unless the primer recognizes disperse repetitive sequences). Second, primers of 8 and 10 nucleotides in length produced identical fingerprint patterns from an array of organisms ranging from bacteria to human. ${ }^{(34,35)}$ Third, cleavage of template DNA with up to five restriction endonucleases with 4 bp-recognition sequences prior to amplification did not decrease the number of amplification products. $^{(34)}$ Destruction of bona fide amplicons by cleavage must then permit amplification of products resulting from at least single mismatch events at the primer $5^{\prime}$ terminus. Fourth, octamers with single base substitutions at the $5^{\prime}$ end were still able to amplify products with defined 8 nucleotide termini by prior amplification. ${ }^{(35)}$ Mismatches in the first 2-3 nucleotides from the 5 ' end allowed amplification of almost all products. Mismatches at positions more distant from the $5^{\prime}$ terminus failed to initiate amplification. Fifth, cloning and sequencing of genomic regions that hybridized to several amplification fragments revealed mismatches at the $5^{\prime}$ terminus. ${ }^{(23)}$

Addition of nucleotides to the $8 \mathrm{nu}$ cleotide domain does not increase the information content of DNA patterns significantly. This observation suggests that longer primers such as those used in other studies $^{(23-25)}$ may not be required. The $5^{\prime}$ terminus of primers of a length comparable with those used in PCR, however, may condition fingerprint pattern significantly. This is expected be- cause long 5'-terminal primer domains may contain regions of partial homology to the template, favoring some amplicons over others.

Other primer characteristics also determine primer-template interactions. Using templates with ends engineered to have perfect homology to the $3^{\prime}$ terminus of the primer, we determined that overhangs in both strands of primertemplate duplexes (produced as a result of differences in primer length) affected the formation of many amplification products. ${ }^{(35)}$ Similarly, fluorophore labels and stable minihairpins at the $5^{\prime}$ terminus of the primer altered fingerprint patterns. $^{(55)}$

Within a $50-100 \%$ GC content, we have not found any influence of fractional primer GC content on amplification. ${ }^{(34)}$ Recently, Fritsch et al. ${ }^{(56)}$ surveyed 480 decamers and found that total GC content had the most predictive value in estimating the efficiency of RAPD amplification. Their results confirmed the previously observed direct correlation between primer GC content and degree of amplification. ${ }^{(24)}$ However, some primers produce markedly fewer amplification products than others, and some produce very few or no products with genomic DNA from a wide range of organisms. ${ }^{(55)}$ The reasons for poor amplification are unclear but may result from the existence of extremely rare oligonucleotide sequences as demonstrated in mammals and other organisms ${ }^{(57-59)}$ or from interference of the secondary structure of target site or product on the amplification of particular sequences.

\section{PARAMETERS AFFECTING AMPLIFICATION}

Several parameters affect the interaction between single strands, duplexes, hairpin loops, and other DNA molecular species formed during MAAP (as depicted by the paradigm of Fig. 1). The use of arbitrary primers requires adequate discrimination of bona fide (i.e., authentic and reproducible) reaction products from those of artifactual origin. This discrimination must coexist with an inherent nonstringent reaction environment determined by the chemistry of the primer. In trying to maintain such fine equilibrium, the levels of reaction components must be carefully optimized. Frequently, temperature is varied to favor the forma- tion of bona fide products. However, varying time intervals, annealing, extension or denaturation temperature, cycle numbers, or even heating and cooling rates can complicate the uniform and simple usage of an amplification technique. Therefore, other parameters like primer, template, and ion concentrations, or the DNA polymerase itself, must be considered.

\section{Reaction Components and Environment}

Using defined primer-template combinations, we followed an iterative process to optimize the DAF reaction carefully for genomes of high ${ }^{(60)}$ and low complexity. ${ }^{(55)}$ Similarly, careful optimization has preceded several studies using RAPD analysis. ${ }^{(52-54,61-63)}$ Fingerprints obtained with different eubacterial DNA polymerases vary considerably and require widely different optima for the various amplification parameters. Generally, truncated DNA polymerases like Stoffel fragment produce clearer fingerprints with a higher proportion of strong primary products, are more tolerant of experimental variables such as primer or enzyme concentration, ${ }^{(60)}$ and reveal increased levels of polymorphic DNA. ${ }^{(55)}$

Several parameters were crucial for generating reproducible fingerprints. When compared with RAPD analysis ${ }^{(24)}$ and PCR, DAF requires $>10$ times more primer $(3 \mu \mathrm{M})$, equal to higher levels of magnesium, and sometimes considerably lower template concentrations. ${ }^{(60)}$ Higher primer concentration often results in increased primer-template mismatching, favoring the required nonstringent reaction conditions of DAF. Consistent fingerprints can be obtained with relatively low levels of magnesium (1.5-4 mM) for templates or high complexity and with high levels (4-8 $\mathrm{mm}$ ) for low-complexity genomes. These requirements vary with ionic components of the reaction, much as described for PCR. ${ }^{(64)}$ To avoid possible stoichiometric misrepresentation of amplicons that are rare or amplify with low efficiency, at least $1 \mathrm{ng} / \mu \mathrm{l}$ or $0.1 \mathrm{ng} / \mu \mathrm{l}$ of template DNA from low- or high-complexity genomes, respectively, must be added. Whereas DNA patterns were consistent over these limits, lower template levels can result in inconsistent fingerprints, with variant bands corresponding to weakly amplified products. ${ }^{(55,60)}$ 
DAF produces fingerprints from prokaryotic and eukaryotic organisms with minimal experimental variability. In contrast, artifactual nongenetic variation in RAPD analysis can be considerable if primer-template concentrations and the annealing temperature are not carefully optimized. ${ }^{(65,66)}$ For example, high and low template concentrations and annealing temperatures produced smears. ${ }^{(32)}$ These effects may be responsible for the failure of RAPD analysis to produce profiles with heptamer and octamer primers known to give complex profiles with DAF.

\section{Thermal Cycling Parameters}

Shorter primers require lower annealing temperatures for adequate amplification. However, a pentamer can still produce DAF products at $\sim 55^{\circ} \mathrm{C} .{ }^{(35)}$ Because these short primer-template duplexes should be unstable at these temperatures, ${ }^{(67)}$ the few primer annealing events that occur allow primer extension and accumulate product. Sequence-related primers of $7-15$ nucleotides in length failed to amplify DNA at annealing temperatures of $65^{\circ} \mathrm{C}-80^{\circ} \mathrm{C} .{ }^{(35)} \mathrm{Tem}$ peratures of $>80^{\circ} \mathrm{C}$ were unable to render profiles with any primer, probably because higher temperatures do not allow adequate primer annealing and extension. While DAF profiles tended to simplify with increasing annealing temperature, trends in pattern distribution and the boundary of the 8-nucleotide primer domain were conserved. The use of "hot start" $(15,16)$ in these experiments did not alter DNA patterns or product yield. DAF appears very tolerant of annealing, extension, and denaturation times; however, other MAAP techniques may not an excessive number of temperature cycles should be avoided, both because of long experimental times and generation of artifacts.

\section{Primer Design}

The design of primer sequence, even if performed using established algorithms, ${ }^{(68,69)}$ is not a random process. Primers are arbitrary from the moment we design their sequence to the inevitable selection of those that are informative and render "useful" DNA polymorphisms. We should then eliminate the word "random" from our lexicon when connected to the amplification of DNA with arbitrary primers, because neither the primers nor the process is random in nature.

Whereas criteria for selection of primers vary with the MAAP technique employed, empirical and theoretical considerations during primer design will help unveil hidden sequences responsible for failed or successful amplifications. Genomic compositional inhomogeneities occur widely and in different scales, ranging from mammalian isochores of high GC content to prokaryotic repeated palindromes. ${ }^{(59)}$ These deviations from randomness should account for some of the departures observed in the calculation of the expected number of amplification products. ${ }^{(34)}$

\section{APPLICATIONS}

AFLPs arise from a variety of mechanisms, including nucleotide substitutions that create or abolish primer sites and insertion, deletion, or inversion of a priming site or of segments between priming sites. DNA rearrangements result in length polymorphisms that sometimes manifest as presence or absence of DNA fragments. These DNA polymorphisms constitute identification tools for genetic typing and mapping.

\section{DNA Fingerprinting, Molecular, Taxonomy, and Population Genetics}

Arbitrary primers can be used to define genetic relationships between organisms in evolutionary, phylogenetic, and taxonomical studies. MAAP strategies also constitute straightforward identification tools for general fingerprinting, whether used in forensic science, clinical pathogen identification, or plant varietal certification. Their versatile nature is suggested by how fingerprints can be easily tailored to be simple or complex by changing amplification components and primer sequence, length, and number. ${ }^{(31)}$ Simple DNA patterns, generally used for genetic mapping, can be obtained with lower primer or magnesium concentrations in RAPD analyses ${ }^{(24)}$ or with shorter primers and higher annealing temperatures in DAF. ${ }^{(25,60)}$ Complex patterns, better suited for DNA fingerprinting applications, can be better produced with engineered DNA polymerases (truncated or cloned versions) or higher magnesium concentration. ${ }^{(55)}$
DNA fingerprints that can group and classify genomes individually are obtained by screening primers and selecting those exhibiting adequate levels of polymorphic DNA. In some cases, few primers can accomplish this task easily, as in the analysis of different isolates of Streptococcus uberis $^{(70)}$ and cultivars of banana. ${ }^{(71)}$ In these studies, DAF matched bacterial subgroup characterization and cultivar classification using physiological, biochemical, and molecular approaches (restriction endonuclease fingerprinting, $16 \mathrm{~S}$ ribosomal DNA analysis, and simple sequence length polymorphism (SSLP) analysis). In contrast, isolates of Discula destructiva were very difficult to separate even after screening many primers. ${ }^{(72)}$ In such cases, other tailoring strategies had to be used. Digestion of template DNA with restriction endonucleases prior to amplification was found to enhance the detection of polymorphic DNA in fingerprints generated with a particular primer. ${ }^{(73)}$ Fungal and plant cultivars that were indistinguishable by DAF with several primers were easily separated in this way.

DAF has been used to characterize a wide range of organisms, ranging from bacteria to human (for review, see refs. 31 and 74). Despite producing simple patterns, RAPD has been used extensively to fingerprint bacteria ${ }^{(52,54,75-77)}$ and fungi, ${ }^{(51,78-83)}$ study phylogenetic and taxonomical relationships in plants, ${ }^{(84-89)}$ and establish molecular relatedness and genetic variation in animals. ${ }^{(50,53,90-92)}$ Moreover, RAPD markers were used successfully in population and pedigree analysis, ${ }^{(93-95)}$ to test interspecific nuclear gene flow in Irises, ${ }^{(96)}$ and to predict evolution of androdioecy in flowering plants. ${ }^{(97)}$ Combined with denaturing gradient-gel electrophoresis, RAPD detected polymorphisms in cereal crop species. ${ }^{(95,98)}$ AP-PCR has been used to study relatedness of Leptospira, ${ }^{(99)} \mathrm{de}$ termine parentage in maize, ${ }^{(100)}$ identify mouse strains, ${ }^{(101)}$ and detect somatic genetic alterations in colorectal tumors. ${ }^{(102)}$

In cases where the template is composed of more than one genome, it is possible to differentiate each organism without resorting to physical separation of the contributing genomes. In the study of the Azolla-Anabaena symbiosis, characteristic DAF profiles for the fern or the microsymbiont were generated by altering primer sequence. ${ }^{(103)}$ 


\section{High-resolution Genetic Mapping}

MAAP has provided genetic markers in biological systems that have not lent themselves easily to study. Genetic linkage analysis in conifers, complicated because of the large size of the genome and the difficult generation of F2 segregating populations, has been possible with the use of arbitrary primers. ${ }^{(61)}$ High-density maps were constructed with unprecedented speed in white spruce ${ }^{(104)}$ and loblolly pine (105) using haploid DNA from megagametophytes. A map of Arabidopsis thaliana with $>250$ RAPD markers was created in only 4 person-months using recombinant inbreds. ${ }^{(106)}$ Similarly, segregation of markers in recombinant inbred strains allowed genomic mapping in mouse. ${ }^{(107)}$ MAAP mapping has been also validated in soybean, ${ }^{(24,73)}$ diploid alfalfa, ${ }^{(108)}$ Brassica, ${ }^{(109)}$ yellow birch, ${ }^{(110)}$ mouse, and rat. ${ }^{(53,101,111)}$

\section{Strategies for Directed Mapping: Analysis of Near-isogenic Lines, Bulked Segregant Analysis, and MAAP of Endonuclease-digested DNA}

MAAP markers can be linked to specific chromosomal regions and can be used to isolate genes of interest without requiring a genetic map of the entire genome. RAPD markers located in regions introgressed during development of near-isogenic lines were identified and found linked to nematode ${ }^{(112)}$ and Pseudomo$n a s^{(113)}$ resistance genes in tomato, or to downy mildew resistance in lettuce. ${ }^{(114)}$ However, near-isogenic lines require extensive backcrossing for their generation and may contain cointrogressed regions of the donor genome that are not linked to the trait in study.

Based on a genome pooling RFLP strategy, ${ }^{(115)}$ bulked segregant analysis $(\mathrm{BSA})^{(116)}$ allows mapping of a gene that segregates in a single population, construction of detailed maps of specific genomic regions, saturation of those regions with markers, or coalescing of unlinked sections of a genetic map. The strategy uses bulked DNA samples from segregating individuals that differ for a specific phenotype or genotype. The bulked samples are screened with arbitrary primers, and polymorphic markers are identified. Variations of this technique were originally used to target regions responsible for disease resistance in lettuce, ${ }^{(116)}$ and fruit ripening and pedicel abscission in tomato. ${ }^{(117)}$

RAPD markers linked to a particular locus using near-isogenic lines or BSA are usually found only after screening hundreds of arbitrary primers. This limitation can be overcome by enhancing the detection of polymorphic DNA. The high information content of DAF fingerprints and digestion of template DNA with restriction endonucleases prior to amplification increase significantly the levels of polymorphism. ${ }^{(73)}$ The strategy uses a limited number of primers to generate diagnostic markers that can distinguish near-isogenic lines or pooled samples in BSA. Using this approach, we differentiated two ethylmethanesulfonate-induced mutants of soybean altered in the $n t s$ locus that controls nodule formation. The supernodulating $n t s$ trait segregates as a single recessive Mendelian locus and is unlinked to two separately isolated non-nodulation loci (for review, see Caetano-Anollés and Gresshoff). ${ }^{(118)}$ Several DAF markers were found tightly linked to the $n t s$ locus after screening only 19 primers (Fig. 3). ${ }^{(73)}$ The abundance of linked markers suggests that a "hot-spot" of mutagenic activity occurred closed to the nts locus.
This endonuclease-linked MAAP strategy can be used efficiently to generate STSs or sequence-characterized amplified regions (SCARs) ${ }^{(119)}$ linked to genes of interest, for high-resolution linkage mapping of specific genomic regions and, potentially, for chromosome walking.

Usually, MAAP markers possess the intrinsic disadvantages of dominance, low allele number, and lack of homology among related taxa. Sometimes, they target dispersed repetitive DNA sequences, making them useless as hybridization probes. In some cases, these characteristics devalue their use as genetic markers or even as sources of conventional RFLPs. ${ }^{(62)}$ Some of these limitations can be overcome if amplification products are sequenced and turned into STSs or SCARs. PCR can then be used reliably to link overlapping clones in physical mapping. ${ }^{(20)}$ Because DAF can fingerprint yeast chromosomes and large genomic DNA fragments isolated by pulse-field gel electrophoresis ${ }^{(121)}$ and can analyze templates composed of more than one genome, ${ }^{(103)}$ MAAP of cloned DNA can conceivably confirm identification of overlaps in yeast artificial chromosomes (YACs) and cosmid libraries. Certain arbitrary primers should

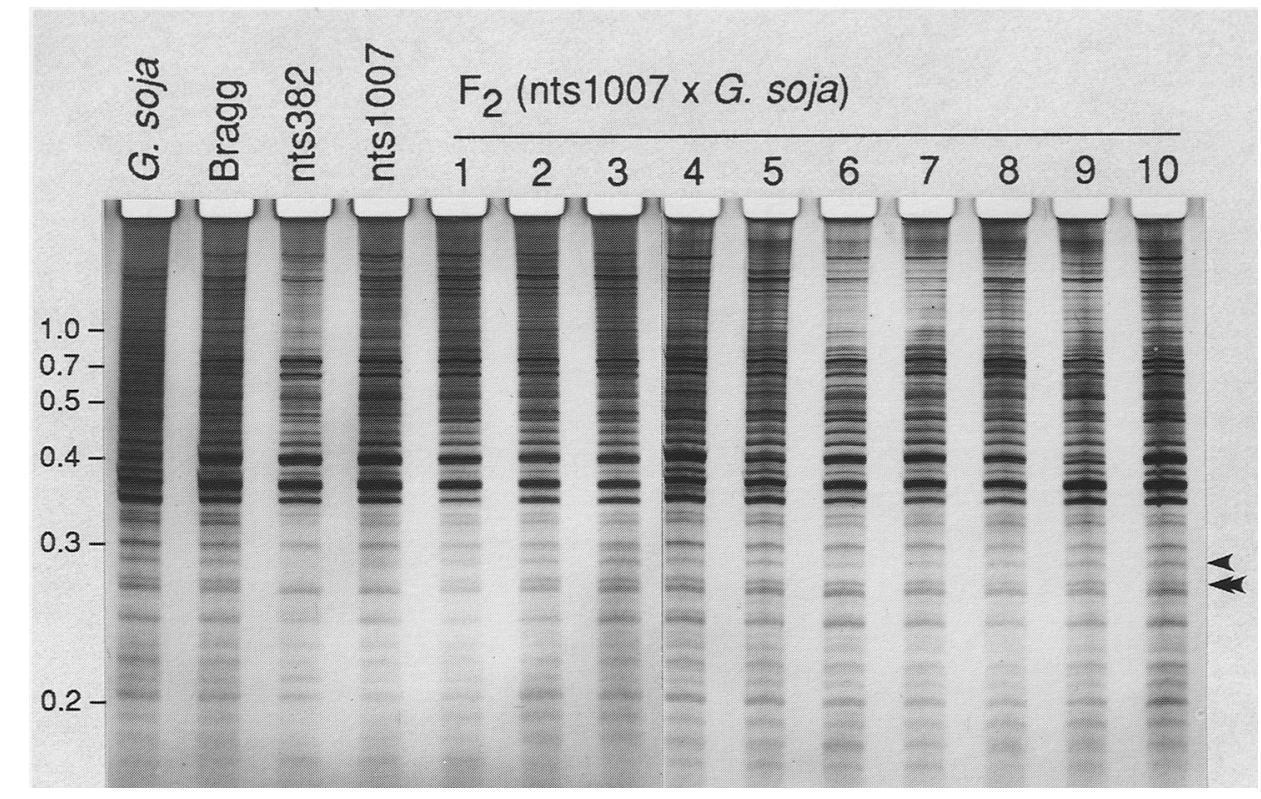

FIGURE 3 Detection of DAF markers linked to the supernodulation $n t s$ locus. DNA from Glycine soja (accession number PI468.397), soybean cultivar Bragg, supernodulating EMS-induced mutant lines nts 382 and nts 1007, and 10 representative supernodulating $F_{2}$ segregants from a cross between G. soja and nts 1007 were digested with MspI, Hinfl, and TaqI and amplified with primer GACGTAGG. Whereas digestion separated Bragg from the $n t s$ mutants, ${ }^{(73)}$ profiles show a 280 -bp AFLP (arrowhead) that also differentiates the $n t s$ allelic mutants. A double arrowhead indicates 1 of 21 AFLPs found tightly liked to the $n t s$ locus after screening only 18 octamer primers. Sizes shown are in $\mathrm{kb}$. 
produce YAC-characteristic fingerprints by amplifying specifically the cloned DNA away from the common yeast genomic DNA background. MAAP would then behave much as Alu-PCR, a technique used specifically to amplify human genomic DNA in YACs. ${ }^{(18)}$

\section{CONCLUSION}

MAAP is a simple and versatile DNA sequence-based diagnostic tool ideally suited for application to many problems in biology, and it can produce fingerprints with greater resolution and information content than ever possible by conventional techniques. Amplification of DNA with arbitrary primers has proven powerful in areas such as identity testing, population and pedigree analysis, and genomic mapping. MAAP has extended the study to prokaryotic and eukaryotic organisms for which little or no prior information was available on their genomes. While automation of MAAP will widen its application, ${ }^{(74)}$ advances in DNA sequencing technology should replace or modify this technique by exploring DNA sequence in toto. I envision the ultimate genetic assay as a tool that efficiently generates DNA markers and reveals their complete DNA sequence, probably by using a direct interface between DNA and an electronic device. No doubt, MAAP will be rapidly daffed (thrust aside), yielding to this novel deus ex machina.

\section{REFERENCES}

1. Landegren, U., R. Kaiser, C.T. Caskey, and L. Hood. 1988. DNA diagnostics. Molecular techniques and automation. Science 242: 229-237.

2. Botstein, D., R.L. White, M.H. Skolnick, and R.W. Davis. 1980. Construction of a genetic map in man using restriction fragment length polymorphisms. Am J. Hum. Genet. 32: 314-331.

3. Mullis, K.B. and F.A. Faloona. 1987. Specific synthesis of DNA in vitro via a polymerase catalysed reaction. Methods Enzymol. 255: 335-350.

4. Mullis, K.B., F.A. Faloona, S. Scharf, R. Saiki, G. Horn, and H. Erlich. 1986. Specific enzymatic amplification of DNA in vitro: The polymerase chain reaction. Cold Spring Harbor Symp. Quant. Biol. 51: 263-273.

5. Jeffreys, A.J., V. Wilson, R. Neumann, and J. Keyte. 1988. Amplification of human minisatellites by the polymerase chain reaction: Towards DNA finger- printing of single cells. Nucleic Acids Res. 16: 10953-10971.

6. Tautz, D. 1989. Hypervariability of simple sequences as a general source of polymorphic DNA markers. Nucleic Acids Res. 17: 6463-6471.

7. Litt, M. and J.A. Luty. 1989. A hypervariable microsatellite revealed by in vitro amplification of a dinucleotide repeat within the cardiac muscle actin gene. Am J. Hum. Genet. 44: 397-401.

8. Weber, J.L. and P.E. May. 1989. Abundant class of human DNA polymorphisms which can be typed using the polymerase chain reaction. Am. J. Hum. Genet. 44: 388-396.

9. Olson, M., L. Hood, C. Cantor, and D. Botstein. 1989. A common language for the physical mapping of the human genome. Science 248: 1434-1435.

10. Guatelli, J.C., K.M. Whitfield, D.Y. Kwoh, K.J. Barrionger, D.D. Richman, and T.R. Gingeras. 1990. Isothermal in vitro amplification of nucleic acids by a multienzyme reaction modeled after retroviral replication. Proc. Natl. Acad. Sci. 87: 1874-1878.

11. Barany, F. 1991a. Genetic disease detection and DNA amplification using cloned thermostable ligase. Proc. Natl. Acad. Sci. 88: 189-193.

12. Barany, F. 1991b. The ligase chain reaction in a PCR world. PCR Methods Applic. 1: $5-16$.

13. Fahy, E., D.Y. Kwoh, and T.R. Gingeras. 1991. Self-sustained sequence replication (3SR): An isothermal transcriptionbased amplification system alternative to PCR. PCR Methods Applic. 1: 25-33.

14. Walker, G.T., M.C. Little, J.G. Nadeau, and D.D. Shank. 1992. Isothermal in vitro amplification of DNA by a restriction enzyme/DNA polymerase system. Proc Natl. Acad Sci. 89: 392-396.

15. Erlich, H.A., D. Gelfand, and J.J. Sninsky. 1991. Recent advances in polymerase chain reaction. Science 252: 1643-1651.

16. Mullis, K.B. 1991. The polymerase chain reaction in an anemic mode: How to avoid cold oligodioxyribonuclear fusion. PCR Methods Applic. 1: 1-4.

17. Arnheim, N. and H. Erlich. 1992. Polymerase chain reaction strategy. Annu. Rev. Biochem. 61: 131-156.

18. Nelson, D.L., S.A. Ledbetter, L. Corbo, M.F. Victoria, R. Ramirez-Solis, T.D. Webster, D.H. Ledbetter, and C.T. Caskey. 1989. Alu polymerase chain reaction: A method for rapid isolation of human-specific sequences from complex DNA sources. Proc. Natl. Acad. Sci. 86: 6686-6690.

19. Versalovic, J., T. Koeuth, and J.R. Lupski. 1991. Distribution of repetitive DNA sequences in eubacteria and applications to fingerprinting of bacterial genomes. Nucleic Acids Res. 19: 6823-6831.
20. Hartley, J.L. 1991. Amplification of nucleic acid sequences using oligonucleotides of random sequence as primers. U.S. Patent No. 5,043,272.

21. Zhang, L., X. Cui, K. Schmitt, R. Hubert, W. Navidi, and N. Arnheim. 1992. Whole genome amplification from a single cell: Implications for genetic analysis. Proc. Natl. Acad. Sci. 89: 5847-5851.

22. Froussard, P. 1993. rPCR: A powerful tool for random amplification of whole RNA sequences. PCR Methods Applic. 2: 185190.

23. Parker, J.D., P.S. Rabinovitch, and G. Burmer. 1991. Targeted gene walking polymerase chain reaction. Nucleic Acids Res. 19: 3055-3060.

24. Williams, J.G.K., A.R. Kubelik, K.J. Livak, J.A. Rafalski, and S.V. Tingey. 1990. DNA polymorphisms amplified by arbitrary primers are useful as genetic markers. Nucleic Acids Res. 18: 6531-6535.

25. Welsh, J. and M. McClelland. 1991. Fingerprinting genomes using PCR with arbitrary primers. Nucleic Acids Res. 18: 7213-7218.

26. Caetano-Anollés, G., B.J. Bassam, and P.M. Gresshoff. 1991. DNA amplification fingerprinting using very short arbitrary oligonucleotide primers. Bio/Technology 9: 553-557.

27. Liang, P. and A.B. Pardee. 1992. Differential display of eukaryotic messenger RNA by means of the polymerase chain reaction. Science 257: 967-971.

28. Welsh, J., K. Chada, S.S. Dalal, R. Cheng, D. Ralph, and M. McClelland. 1992. Arbitrarily primed PCR fingerprinting of RNA. Nucleic Acids Res. 20: 4965-4970.

29. Loh, E.Y., F.F. Elliott, S. Cwirla, L.L. Lanier, and M.M. Davis. 1989. Polymerase chain reaction with single sided specificity: Analysis of a T-cell receptor delta chain. Science 243: 217-220.

30. Caetano-Anollés, G., B.J. Bassam, and P.M. Gresshoff. 1992. DNA fingerprinting: MAAPing out a RAPD redefinition? Bio/Technology 10: 937.

31. Caetano-Anollés, G., B.J. Bassam, and P.M. Gresshoff. 1991. DNA amplification fingerprinting: A strategy for genome analysis. Plant. Mol. Biol. Rep. 9: 292305.

32. Tingey, S.V. and J.P. del Tufo. 1993. Genetic analysis with random amplified polymorphic DNA markers. Plant Physiol. 101: 349-352.

33. Bassam, B.J., G. Caetano-Anollés, and P.M. Gresshoff. 1991. Fast and sensitive silver staining of DNA in polyacrylamide gels. Anal. Biochem. 80: 81-84.

34. Caetano-Anollés, G. 1993. Multiple arbitrary amplicon profiling using single oligonucleotide primers: Theoretical considerations and implications in primertemplate interaction. (in prep.).

35. Caetano-Anollés, G., B.J. Bassam, and 
P.M. Gresshoff. 1992. Primer-template interactions during DNA amplification fingerprinting with single arbitrary oligonucleotides. Mol. \& Gen. Genet. 235: 157-165.

36. Mendelman, L.V., J. Petruska, and M.F. Goodman. 1990. Base mispair extension kinetics. Comparison of DNA polymerase $\alpha$ and reverse transcriptase. $J$. Biol. Chem. 265: 2338-2346.

37. Creighton, S., M. Huang, H. Cai, N. Arnheim, and M.F. Goodman. 1992. Base mispair extension kinetics. Binding of avian myeloblastosis reverse transcriptase to matched and mismatched base pair termini. J. Biol. Chem. 267: 2633-2639.

38. Huang, M., N. Arnheim, and M.F. Goodman. 1992. Extension of base mispairs by Taq DNA polymerase: Implications for single nucleotide discrimination in PCR. Nucleic Acids Res. 20: 4567-4573.

39. Yu, H. and M.F. Goodman. 1992. Comparison of HIV-1 and avian myeloblastosis virus reverse transcriptase fidelity on RNA and DNA templates. J. Biol. Chem. 267: 10888-10896.

40. Beese, L.S., V. Derbyshire, and T.A. Steitz. 1993. Structure of DNA polymerase I Klenow fragment bound to duplex DNA. Science 260: 352-355.

41. Kolocheva, T.I., G.A. Nevinsky, V.A. Volchkova, A.S. Levina, V.V. Khomov, and O.I Lavrik. 1989. DNA polymerase I (Klenow fragment): Role of the structure and length of a template in enzyme recognition. FEBS Lett. 248: 97-100.

42. Polesky, A., M.E. Dahlberg, S.J. Benkovic, N.D.F. Grindley, and C.M. Joyce. 1992. Side chains involved in catalysis of the polymerase reaction of DNA polymerase I from Escherichia coli. J. Biol. Chem. 267: 8417-8428.

43. Sommer, R. and D. Tautz. 1989. Minimal homology requirements for PCR primers. Nucleic Acids Res. 17: 6749.

44. Wu, D.Y., L. Ugozzoli, B.K. Pol, and R.B. Wallace. 1989. Allele-specific enzymatic amplification of $\beta$-globin genomic DNA for diagnosis of sickle cell anemia. Proc. Natl. Acad. Sci. 86: 2759-2760.

45. Nichols, W.C., J.J. Liepnieks, V.A. McKusick, and M.D. Benson. 1989. Direct sequencing of the gene for Maryland/German familial amyloidic polyneuropathy type II and genotyping by allele-specific enzymatic amplification. Genomics 5: 535-540.

46. Ehlen, T. and L. Dubeau. 1989. Detection of RAS point mutations by polymerase chain reaction using primer mutation-specific, inosine-containing oligonucleotide primers. Biochem. Biophys. Res. Commun. 160: 441-447.

47. Newton, C.R., A. Graham, L.E. Heptinstall, S.J. Powell, C. Summers, N. Kalsheker, J.C. Smith, and A.F.
Markham. 1989. Analysis of any point mutation in DNA: The amplification refractory mutation system (ARMS). Nucleic Acids Res. 17: 2503-2516.

48. Okayama, H., D.T. Curiel, M.L. Brantly, M.D. Holmes, and R.G. Crystal. 1989. Rapid, nonradioactive detection of mutations in the human genome by allelespecific amplification. J. Lab. Clin. Med. 114: 105-113.

49. Kwok, S., D.E. Kellogg, N. McKinney, D. Spasic, L. Goda, C. Levenson, and J.J. Sninsky. 1990. Effects of primer-template mismatches on the polymerase chain reaction: Human immunodeficiency virus type 1 model studies. $\mathrm{Nu}$ cleic Acids Res. 18: 999-1005.

50. Owen, J.L. and C.M. Uyeda. 1991. Single primer amplification of avian genomic DNA detects polymorphic loci. Animal Biotechnol. 2: 107-122.

51. Crowhurst, R.N., B.T. Hawthorne, E.H.A Rikkerink, and M.D. Templeton. 1991. Differentiation of fusarium solani $\mathrm{f}$. $\mathrm{sp}$. cucurbitae races 1 and 2 by random amplification of polymorphic DNA. Curr. Genet. 20: 391-396.

52. Akopyanz, N., N.O. Bukanov, T.U. Westblom, S. Kresovic, and D.E. Berg. 1992. DNA diversity among clinical isolates of Helicobacter pylori detected by PCR-based RAPD fingerprinting. Nucleic Acids Res. 20: $5137-5142$.

53. Nadeau, J.H., H.G. Bedigian, G. Bouchard, T. Denial, M. Kosowsky, R. Norberg, S. Pugh, E. Sargeant, R. Turner, and B. Paigen. 1992. Multilocus markers for mouse genome analysis: PCR amplification based on single primers of arbitrary nucleotide sequence. Mammalian Genome 3: 55-64.

54. Fekete, A., J.A. Bantle, S.M. Halling, and R.W. Stich. 1992. Amplification fragment length polymorphism in Brucella strains by use of polymerase chain reaction with arbitrary primers. $J$. Bacteriol. 174: 7778-7783.

55. Caetano-Anollés, G. and B.J. Bassam, unpubl.

56. Fritsch, P., M.A. Hanson, C.D. Spore, P.E. Pack, and L.H. Rieseberg. 1993. Constancy of RAPD primer amplification strength among distantly related taxa of flowering plants. Plant Mol. Biol. Rep. 11: $10-20$.

57. Volinia, S., R. Gambari, F. Bernardi, and I. Barrai. 1989. The frequency of oligonucleotides in mammalian genic regions. Comp. Appl. Biosci. 5: 33-40.

58. Burge, C., A.M. Campbell, and S. Karlin. 1992. Over- and under-representation of short oligonucleotides in DNA sequences. Proc. Natl. Acad. Sci. 89: 1358-1362.

59. Karlin, S. and V. Brendel. 1992. Chance and statistical significance in protein and DNA sequence analysis. Science 257: $39-49$.
60. Bassam, B.J., G. Caetano-Anollés, and P.M. Gresshoff. 1992. DNA amplification fingerprinting of bacteria. Appl. Microbiol. Biotechnol. 38: 70-76.

61. Carlson, J.E., L.K. Tulsieram, J.C. Glaubitz, V.W.K. Luk, C. Kauffeldt, and R. Rutledge. 1991. Segregation of random amplified DNA markers in $\mathrm{F}_{1}$ progeny of conifers. Theor. Appl. Genet. 83: 194-200.

62. Devos, K.M. and M.D. Gale. 1992. The use of random amplified polymorphic DNA markers in wheat. Theor. Appl. Genet. 84: 567-572.

63. Munthali, M., B.V. Ford-Lloyd, and H.J. Newbury. 1992. The random amplification of polymorphic DNA for fingerprinting plants. PCR Methods Applic. 1: 274-276.

64. Blanchard, M.M., P. Taillon-Miller, P. Nowotny, and V. Nowotny. 1993. PCR buffer optimization with uniform temperature regimen to facilitate automation. PCR Methods Applic. 2: 234-240.

65. Ellsworth, D.L., K.D. Rittenhouse, and R.L. Honeycutt. 1993. Artifactual variation in randomly amplified polymorphic DNA banding patterns. BioTechniques 14: 214-217.

66. Muralidharan, K. and E.K. Wakeland. 1993. Concentration of primer and template qualitatively affects products in random-amplified polymorphic DNA PCR. BioTechniques 14: 362-364.

67. Rychlik, W., W.J. Spencer, and R.E. Rhoads. 1990. Optimization of the annealing temperature for DNA amplification in vitro. Nucleic Acids Res. 18: 64096412.

68. Ferrenberg, A.M., D.P. Landau, and Y.J. Wong. 1992. Monte Carlo simulations: Hidden errors from "good" random number generators. Phys. Rev. Lett. 69: 3382-3384.

69. Hayes, B. 1993. The wheel of fortune. Amer. Sci. 81: 114-118.

70. Jayarao, B.M., B.J. Bassam, G. CaetanoAnollés, P.M. Gresshoff, and S.P. Oliver. 1992. Subtyping Streptococcus uberis by DNA amplification fingerprinting. $J$. Clin. Microbiol. 30: 1347-1350.

71. Kaemmer, D., R. Afza, K. Weising, G. Kahl, and F.J. Novak. 1992. Oligonucleotide and amplification fingerprinting of wild species and cultivars of banana (Musa spp.) Bio/Technology 10: 1030 1035.

72. Trigiano, R., G. Caetano-Anollés, B.J. Bassam, K.R. Weaver, M.T. Windham, and P.M. Gresshoff. 1992. DNA amplification fingerprinting of dogwood anthracnose fungi. Proc. South. Nurs. Assoc. 37: 196-199.

73. Caetano-Anollés, G., B.J. Bassam, and P.M. Gresshoff. 1993. Enhanced detection of polymorphic DNA by multiple arbitrary amplicon profiling of endonu- 
clease digested DNA: Identification of markers linked to the supernodulation locus in soybean. Mol. \& Gen. Genet. 241: $57-64$.

74. Caetano-Anollés, G., B.J. Bassam, and P.M. Gresshoff. 1992c. DNA amplification fingerprinting with very short primers. In Application of RAPD technology to plant breeding, pp. 18-25. CSSA-ASHSAGA, Minneapolis, MN.

75. Mazurier, S., A. Andurier, N. MarquetVan de Mee, S. Notermans, and K. Wernars. 1992. A comparative study of randomly amplified polymorphic DNA analysis and conventional phage typing for epidemiological studies of Listeria monocytogenes isolates. Res. Microbiol. 143: 507-512.

76. Mazurier, S., A. van de Giessen, K. Heuvelman, and K. Wernars. 1992. RAPD analysis of Campylobacter isolates: DNA fingerprinting without the need to purify DNA. Lett. Appl. Microbiol. 14: 260262.

77. Mazurier, S. and K. Wernars. 1992. Typing of Listeria strains by random amplification of polymorphic DNA. Res. Microbiol. 143: 499-505.

78. Goodwin, P.H. and S. Annis. 1991. Rapid identification of genetic variation and pathotype of Lepthosphaeria maculans by random amplified polymorphic DNA assay. Appl. Environ. Microbiol. 57: 24822486.

79. Smith, M.L., J.N. Bruhn, and J.B. Anderson. 1992. The fungus Armillaria bulbosa is among the largest and oldest living organisms. Nature 356: 428-431.

80. Kersulyte, D., J.P. Woods, E.J. Keath, W.E. Goldman, and D.E. Berg. 1992. Diversity among clinical isolates of Histoplasma capsulatum detected by polymerase chain reaction with arbitrary primers. J. Bacteriol. 174: 7075-7079.

81. Sellstedt, A., B. Wullings, U. Nyström, and P. Gustafsson. 1992. Identification of Casuarina-Frankia strains by use of polymerase chain reaction (PCR) with arbitrary primers. FEMS Microbiol. Lett. 93: 1-6.

82. Khush, R.S., E. Becker, and M. Wach. 1992. DNA amplification polymorphisms of the cultivated mushroom Agaricus bisporus. Appl. Environ. Microbiol. 58: 2971-2977.

83. Haemmerli, U.A., U.E. Brändle, O. Petrini, and J.M. McDermott. 1992. Differentiation of isolates of Discula umbrinella (Teleomorph: Apiognomonia errabunda) from beech, chestnut, and oak using randomly amplified polymorphic DNA markers. Mol. Plant-Microbe Interact. 5: 479-483.

84. Hu, J. and C.F. Quiros. 1991. Identification of broccoli and cauliflower cultivars with RAPD markers. Plant Cell Rep. 10: $505-511$.
85. Halward, T., T. Stalker, E. LaRue, and G. Kochert. 1992. Use of single-primer DNA amplifications in genetic studies of peanut (Arachis hypogaea L.). Plant Mol. Biol. 18: 315-325.

86. Wilde, J., R. Waugh, and W. Powell. 1992. Genetic fingerprinting of Theobroma clones using randomly amplified polymorphic DNA markers. Theor. Appl. Genet. 83: 871-877.

87. Vierling, R.A. and H.T. Nguyen. 1992. Use of RAPD markers to determine the genetic diversity of diploid, wheat genotypes. Theor. Appl. Genet. 84: 835-838.

88. Demeke, T., R.P. Adams, and R. Chibbar. 1992. Potential taxonomic use of random amplified polymorphic DNA (RAPD): A case study in Brassica. Theor. Appl. Genet. 84: 990-994.

89. Kresovich, S., J.G.K. Williams, J.R. McFerson, E.J. Routman, and B.A. Schaal. 1992. Characterization of genetic identities and relationships of Brassica oleracea $\mathrm{L}$. via a random amplified polymorphic DNA assay. Theor. Appl. Genet. 85: 190-196.

90. Black, W.C. IV, N.M. DuTeau, G.J. Puterka, J.R. Nechols, and J.M. Pettorini. 1992. Use of random amplified polymorphic DNA polymerase chain reaction (RAPD-PCR) to detect DNA polymorphisms in aphids (Homoptera: Aphididae). Bull. Entomol. Res. 82: 151-159.

91. Hunt, G.J. and R.E. Page Jr. 1992. Patterns of inheritance with RAPD molecular markers reveal novel types of polymorphism in the honey bee. Theor. Appl. Genet. 85: 15-20.

92. Perring, T.M., A.D. Cooper, R.J. Rodriguez, C.A. Farrar, and T.S. Bellows Jr. 1993. Identification of whitefly species by genomic and behavioral studies. Science 259: 74-77.

93. Pellissier-Scott, M., K.M. Haymes, and S.M. Williams. 1992. Parentage analysis using RAPD PCR. Nucleic Acids Res. 20: 5493.

94. Van Heusden, A.W and K. Bachmann. 1992. Genotype relationships in Microseris elegans (Asteraceae, Lactuceae) revealed by DNA amplification from arbitrary primer RAPDs. Plant Syst. Evol. 179: 221-233.

95. Dweikat, I., S. Mckenzie, M. Levy, and H. Ohm. 1993. Pedigree assessment using RAPD-DGGE in cereal crop species. Theor. Appl. Genet. 85: 497-505.

96. Arnold, M.L., C.M. Buckner, and J.J. Robinson. 1991. Pollen-mediated introgression and hybrid speciation in Luisiana irises. Proc. Natl. Acad. Sci. 88: 13981402.

97. Fritsch, P. and L.H. Rieseberg. 1992. High outcrossing rates maintain male and hermaphrodite individuals in populations of the flowering plant Datisca glomerata. Nature 359: 633-636.
98. He, S., H. Ohm, and S. Mckenzie. 1992. Detection of DNA sequence polymorphisms among wheat varieties. Theor. Appl. Genet. 84: 573-578.

99. Ralph, D., M. McClelland̆, J. Welsh, G. Baranton, and P. Perolat. 1993. Leptospira species categorized by arbitrarily primed polymerase chain reaction (PCR) and by mapped restriction polymorphisms in PCR-amplified rRNA genes. J. Bacteriol. 175: 973-981.

100. Welsh, J., R.J. Honeycutt, M. McClelland, and B.W.S. Sobral. 1991. Parentage determination in maize hybrids using the arbitrarily primed polymerase chain reaction (AP-PCR). Theor. Appl. Genet. 82: 473-476.

101. Welsh, J., C. Petersen, and M. McClelland. 1991. Polymorphisms generated by arbitrarily primed PCR in the mouse: Application to strain identification and genetic mapping. Nucleic Acids Res. 19: 303-306.

102. Peinado, M.A., S. Malkhosyan, A. Velazquez, and M. Perucho. 1992. Isolation and characterization of allelic losses and gains in colorectal tumors by arbitrarily primed polymerase chain reaction. Proc. Natl. Acad. Sci. 89: 1006510069.

103. Eskew, D., G. Caetano-Anollés, B.J. Bassam, and P.M. Gresshoff. 1993. DNA amplification fingerprinting of the AzollaAnabaena symbiosis. Plant Mol. Biol. 21: 363-373.

104. Tulsieram, L.K., J.C. Glaubitz, G. Kiss, and J.E. Carlson. 1992. Single tree genetic linkage mapping in conifers using haploid DNA from megagametophytes. Bio/Technology 10: 686-690.

105. Grattapaglia, D., P. Wilcox, J.X. Chaparro, D.M. O'Malley, S. McCord, R. Whetten, L. McIntyre, and R. Sederoff. 1991. A RAPD map of loblolly pine in 60 days. Intl. Soc. Plant Mol. Biol., Congress Proc. Abstr. 2224.

106. Reiter, R.S., J. Williams, K.A. Feldmann, J.A. Rafalski, S.V. Tingey, and P.A. Scolnik. 1992. Global and local genome mapping in Arabidopsis thaliana by using recombinant inbred lines and random amplified polymorphic DNAs. Proc. Natl. Acad. Sci. 89: 1477-1481.

107. Woodward, S.R., J. Sudweeks, and C. Teuscher. 1992. Random sequence oligonucleotide primers detect polymorphic DNA products which segregate in inbred strains of mice. Mammalian Genome 3: 73-78.

108. Echt, C.S., L.A. Erdahl, and T.J. McCoy. 1991. Genetic segregation of random amplified polymorphic DNA in diploid cultivated alfalfa. Genome 35: 84-87.

109. Quiros, C.F., J. Hu, P. This, A.M. Chevre, and M. Delseny. 1991. Development and chromosomal localization of genomespecific markers by polymerase chain re- 
action in Brassica. Theor. Appl. Genet. 82: 627-632.

110. Roy, A., N. Frascaria, J. MacKay, and J. Bousquet. 1992. Segregating random amplified polymorphic DNAs (RAPDs) in Betula alleghaniensis. Theor. Appl. Genet. 85: 173-180.

111. Serikawa, T., X. Montagutelli, D. SimonChazottes, and J. Guénet. 1992. Polymorphisms revealed by PCR with single, short-sized, arbitrary primers are reliable markers for mouse and rat gene mapping. Mammalian Genome 3: 65-72.

112. Klein-Lankhorst, R.M., A. Vermunt, R. Weide, T. Liharska, and P. Zabel. 1991. Isolation of molecular markers for tomato (L. esculentum) using random amplified polymorphic DNA (RAPD). Theor. Appl. Genet. 83: 108-114.

113. Martin, G.B., J.G.K. Williams, and S.D. Tanksley. 1991. Rapid identification of markers linked to a Pseudomonas resistance gene in tomato by using random primers and near-isogenic lines. Proc. Natl. Acad. Sci. 88: 2336-2340.

114. Paran, I., R.V. Kesseli, and R.W. Michelmore. 1991. Identification of RFLP and RAPD markers to downy mildew resistance genes in lettuce with near isogenic lines. Genome 35: 1021-1027.

115. Arnhein, N., C. Strange, and H. Erlich. 1985. Use of pooled DNA samples to detect linkage disequilibrium of polymorphic restriction fragments and human disease: Studies of the $H L A$ class II loci. Proc. Natl. Acad. Sci. 82: 6970-6974.

116. Michelmore, R.W., I. Paran, and R.V. Kesseli. 1991. Identification of markers linked to disease-resistance genes by bulked segregant analysis: A rapid method to detect markers in specific genomic regions by using segregating populations. Proc. Natl. Acad. Sci. 88: 98289832.

117. Giovannoni, J.J., R.A. Wing, M.W. Ganal, and S.D. Tanksley. 1991. Isolation of molecular markers from specific chromosomal intervals using DNA pools from existing mapping populations. $\mathrm{Nu}$ cleic Acids Res. 19: 6553-6558.

118. Caetano-Anollés, G. and P.M. Gresshoff. 1991. Plant genetic control of nodulation in legumes. Annu. Rev. Microbiol. 45: $345-382$.

119. Paran, I and R.W. Michelmore. 1993. Development of reliable PCR-based markers linked to downy mildew resistance genes in lettuce. Theor. Appl. Genet. 85: $985-993$.

120. Green, E.D. and P. Green. 1991. Sequence-tagged site (STS) content mapping of human chromosomes: Theoretical considerations and early experiences. PCR Methods Applic. 1: 7790.

121. Kolchinsky, A.M., R.P. Funke, and P.M. Gresshoff. 1993. DAF-amplified frag- ments can be used as markers for DNA from pulse field gels. BioTechniques 14: $400-403$ 


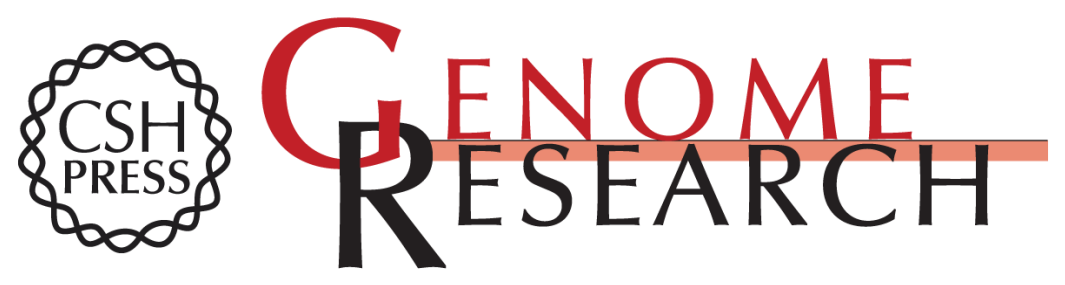

\title{
Amplifying DNA with arbitrary oligonucleotide primers.
}

\author{
G Caetano-Anollés
}

Genome Res. 1993 3: 85-94

Access the most recent version at doi:10.1101/gr.3.2.85

References This article cites 116 articles, 29 of which can be accessed free at:

http://genome.cshlp.org/content/3/2/85.full.html\#ref-list-1

\author{
License
}

Email Alerting Receive free email alerts when new articles cite this article - sign up in the box at the Service top right corner of the article or click here.

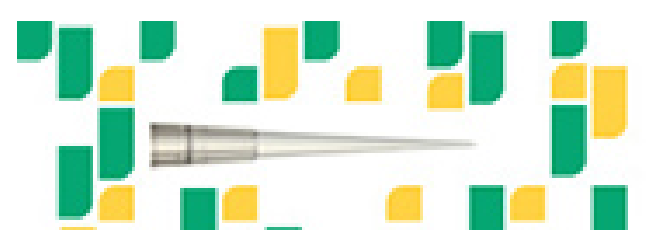

To subscribe to Genome Research go to: https://genome.cshlp.org/subscriptions 